\title{
Knowledge And Attitude Regarding Herbal Products And Their Usage Among Dental House Surgeons Of Belagavi City- A Cross Sectional Study
}

\author{
Shivayogi M.*, Mounica Reddy, Niraj Gokhale, Sagar Jalihal, Chandrashekhar Badkar, Vidyavathi H. Patil \\ Department of Pedodontics and Preventive Dentistry, KLE Academy of Higher Education and \\ Research, KLE VK Institute of Dental, Sciences, Belagavi 590010
}

\begin{abstract}
Background: As herbal therapies are increasingly being used around the world because they are perceived to be free of side effects, it is important that prescriber should be made aware of their possible harm or herbal drug interaction. The need for the study is to impart knowledge to the dentist bout the usage of herbal products and their safety concern and potential drug interaction

Method: This is the cross sectional questionnaire study conducted among dental house surgeons of Belagavi City.To assess the knowledge and attitude of the dental house surgeonstowards the use of herbal extracts in dentistry.One hundred and twenty participants were recruited in a convenient sampling cross-sectional survey. A pretested self reported questionnaire was used and results were analyzed.Reliability of the questionnaire was tested using Cronbach's alpha which was found to be 0.78. Data were analyzed using SPSS 21.

Results: From the present study, it was seen that the participants do not have adequate knowledge regarding usage of herbal products in dentistry.

Conclusion: We concluded that dental house surgeons do not have sufficient knowledge about the usage of herbal products in dentistry. It seems that traditional educational models are not efficient and government with other non-governmental organizations should emphasize to advocate motivational education methods including health belief model and motivational interview at undergraduate levels. Younger students and dentists may have less motivation to change their attitude and behaviour so that we can focus our interventions on these groups.
\end{abstract}

Keywords: Attitude, Dentists, Education, Herbal Products, Knowledge

\section{Introduction}

Herbal medicines have been used for thousands of years - desire for good health. These alternative therapies are quickly gaining importance as they are perceived to be free of side effects, considering their natural origin. Herbs are plants which are used medicinally or for flavour or scent. Herbal extracts with medicinal properties have been effected source of treatment for various disease processes, In dentistry the herbal extracts are used for reducing inflammation, as antimicrobial plaque agents, for preventing release of histamines and as antiseptics, antioxidants, antimicrobials, anti-fungal, antibacterial, antiviral and analgesics. They also aid in healing and are effective in controlling microbial plaque in gingivitis and periodontitis, thereby improving immunity.

The knowledge and correct behaviour in dentists about herbal products can play and important role in treatment of many dental related problems in place of western medicine, unani etc. which are known to have many side effects.[1] However there is a scarcity of literature regarding the knowledge and attitude regarding herbal products and their usage among dental house surgeons. Hence this study was carried out to assess the knowledge and attitude regarding herbal products and their usage among dental house surgeons of Belagavi city.

\section{Subjects and Methods}

The present cross-sectional questionnaire study was conducted among dental surgeons of Belagavi city. After Ethical approval was obtained from the Institutional Review Board a pretested questionnaires consisting of 20 items was distributed to ten subjects to confirm the validity. In the pilot study, the respondents were asked for feedback on clarity of the questions and whether they faced any difficulty in answering the question. Reliability of the questionnaire was checked using Cronbach's alpha and the value obtained was 0.78 . The study was explained to the subjects beforehand and volunteered participants were asked to assemble in a lecture hall on a predetermined date and time, according to convenience of subjects. Written informed consent was obtained and the questionnaires were distributed to the subjects after giving instructions. Subsequently, the forms were collected immediately from all the respondents and the surveys were kept anonymous. The completed forms were compiled and the data collected was analyzed with the SPSS 21 (IBM SPSS Statistics 21, SPSS South Asia, Bangalore, India) 


\section{Results}

In the present study, all the 120 participants returned the completed filled questionnaire. The study included 33.3\% of male population and $66.7 \%$ of female population, which could be related to the more number of female students in the institution.

Table 1: Questionnaire and the responses got.

\begin{tabular}{|c|c|c|c|c|}
\hline \multirow[t]{2}{*}{ S.No. } & \multirow[t]{2}{*}{ Questions } & \multicolumn{3}{|c|}{ Frequency } \\
\hline & & Yes & No & Did not use \\
\hline 1 & Are you aware that natural products can be used as medicines? & 100 & & \\
\hline 2 & Have you used herbal products & 89.2 & 10.8 & \\
\hline 3 & Was the treatment effective? & 73.3 & 15.8 & 10.8 \\
\hline 4 & Any side effects observed? & 5.8 & 83.3 & 10.8 \\
\hline 5 & Are you aware that herbal products can be used in dentistry? & 81.7 & 18.3 & \\
\hline 6 & $\begin{array}{l}\text { Do you feel usage of these herbal products is equivalent to } \\
\text { allopathic? }\end{array}$ & 23.3 & 76.7 & \\
\hline 7 & Are you aware of various herbal toothpastes available? & 96.7 & 3.3 & \\
\hline 8 & $\begin{array}{l}\text { Do you feel they are effective compared to conventional } \\
\text { toothpastes? }\end{array}$ & 23.3 & 76.7 & \\
\hline 9 & $\begin{array}{l}\text { Do you know that remineralization can be possible with herbal } \\
\text { extracts? }\end{array}$ & 12.5 & 87.5 & \\
\hline 10 & $\begin{array}{l}\text { Do you know that herbal extracts can be used in Pediatric } \\
\text { endodontics? }\end{array}$ & 23.3 & 76.7 & \\
\hline 11 & $\begin{array}{l}\text { Are you aware of the herbal extracts used in endodontic } \\
\text { treatment of adults? }\end{array}$ & 20.8 & 79.2 & \\
\hline 12 & $\begin{array}{l}\text { Do you know that candidiasis and denture stomatitis can be } \\
\text { treated with herbal products? }\end{array}$ & 19.2 & 80.8 & \\
\hline 13 & $\begin{array}{l}\text { Do you know that Lichen Planus can be treated with herbal } \\
\text { products? }\end{array}$ & 14.2 & 85.8 & \\
\hline 14 & $\begin{array}{l}\text { Are you aware of the herbal products used to treat oral } \\
\text { malodour? }\end{array}$ & 53.3 & 46.7 & \\
\hline 15 & $\begin{array}{l}\text { Are you aware of the herbs that can be used in gingival and } \\
\text { periodontal problems? }\end{array}$ & 37.5 & 62.5 & \\
\hline 16 & $\begin{array}{l}\text { Are you interested in seeking knowledge about the above herbs } \\
\text { and their uses in dentistry? }\end{array}$ & 86.7 & 13.3 & \\
\hline 17 & $\begin{array}{l}\text { Do you think physiology of herbs and their mechanism of action } \\
\text { along with their uses should be taught in undergraduate level? }\end{array}$ & 80.8 & 18.2 & \\
\hline \multirow[t]{4}{*}{ Question } & Elders at Home & Media & $\begin{array}{l}\text { Friend } \\
\text { Advice }\end{array}$ & \\
\hline & What was the source of information regarding the product? & 48.2 & 39.7 & 12.1 \\
\hline & Question & Herbal & Allopathic & \\
\hline & What is your preference of treatment? & 35.3 & 64.7 & \\
\hline \multirow[t]{2}{*}{ Question } & They are natural without side effects & $\begin{array}{c}\text { They promote } \\
\text { general well } \\
\text { being }\end{array}$ & $\begin{array}{l}\text { Family } \\
\text { tradition }\end{array}$ & \\
\hline & If herbal products are preference, mark the reason & 36.7 & 6.7 & 56.7 \\
\hline
\end{tabular}




\section{Discusion}

This survey highlights the familiarity of students with herbal products and their use as an alternative to the conventional medicine. The prevalence of herb drug usage in the present study is found to be similar to the previous studies which have reported $89.2 \%$ usage for herb and dietary supplementation among college and university students. [2,3] Most common ailment associated with the use of herbal remedies was found to be cough and cold which was also reported by Gardiner et al who mentioned cough \& cold, stomach or intestinal conditions as the most common ones for herb use among young adults in United States (US).[4]

Consistent with a study in 1000 university students in US, the present study found family to be a major source of information and recommendation concerning herbal product use.[5] Similarly, Kara, and Rivera et al reported from studies in the Turkey and USA respectively that people generally follow the trusted advice of family members and friends.[6,7] Reliance on the family advice about herbal use indicates a general lack of scientific attitude among users. Herbal remedies are as old as humankind but their traditional use is not a good indicator of its efficacy. There are many herbal medicines whose efficacy is established by placebo controlled randomized controlled trials. Only those medications which have a sufficient scientific evidence to support their use should be relied upon, instead of blindly following friend or family advice.[8]

Informing their doctors about the simultaneous herbal medicine use was uncommon among the respondents and the reasons cited for non-disclosure mirrors some of the reasons mentioned in the previous studies. In another study conducted on young adult patients in US, only $24 \%$ disclosed the use of herbal products to their health care professional. Similarly, poor communication between patients and health care professionals regarding herbal product use was also reported by other studies. Respondents using herbal medicines without informing the treating physician may have to bear the brunt of serious clinical implications due to the possible herb-drug interactions. It has been found that herbal products interact or interfere with the normal pharmacology of some drugs with potentially fatal consequences. Ginkgo biloba, for example has been associated with bleeding, especially when combined with conventional antithrombotics or anticoagulants. [9] Similarly garlic and ginkgo biloba both have an antiplatelet constituent and hence should be used with caution with other antiplatelet drugs. Cases reporting spinal hemorrhage caused by combined use of ginkgo biloba and high dose of acetaminophen are documented in literature. St John's wort has become the most documented herbal product which is involved in drug interactions. This gives a clear message that all the physicians should routinely include questions related to the use of herbal medicines into their history taking, so as to avoid potentially serious consequences. Rather it is imperative that both physicians and consumers should be aware of the side effects and possibility of potential herb-drug interactions. [10]

The side effects reported with the use of neem tablets emphasize the fact that herbal products are complex mixture of organic and inorganic chemicals, which are further modified during extraction, compounding and packaging for the market use, thereby drifting them away from their original traditional milieu. This might cause a negative impact on the patients' health. [11]

Until now there were no regulations or legal standards that apply to harvesting, processing or packaging of herbal products. But recently in 2011, initiative was taken up in this direction in United Kingdom where Medicines and Healthcare products regulatory agency (MHRA) was set up. It is now mandatory for all herbal remedies to be registered with MHRA. Product packaging of these herbal remedies will display a traditional herbal registration (THR) certification mark which will establish their required standards for safety, quality and evidence of traditional use. This will help in minimizing the use of potential harmful products among users. [12]

Majority of the participants preferring herbal medicine over allopathic medicine indicated their belief on the efficacy and safety of herbal products reflecting a positive attitude towards using these medications. At the same time quoting "Herbs are natural with no side effects" reflected their lack of knowledge and exposure to herbal medicines in their formal education. Keeping in view the sharp upward trend in the acceptance of herbal substances as part of mainstream health milieu, the need of the hour is to increase awareness and knowledge about safety, potential harmful effects, herb-drug interaction and rational use of such medicines. [13] [Table 1]

This can be achieved by organizing continuing medical education programs or incorporating relevant topics in herbal medicine in pharmacology curriculum, as majority of the students in this study also expressed their will to know more about these drugs. This will go a long way in ensuring rational use of herbal products among students and preparing future clinicians. [14]

\section{Conclusion}

From the results of the study, it can be shown that house surgeons lack the knowledge and the right attitude about 
the usage of herbal products in dentistry. From the results obtained, there exists a lacuna in the knowledge of herbal products and the knowledge being translated into the benefits of alternative natural therapies. Thus, knowledge getting transformed into attitude should be channelized through the means of continuing dental programs or through advertisements.

\section{References}

1. Sekhria K, Bhanwrab S, Nandha Ruchika. Herbal products: a survey of students' perception and knowledge about their medicinal use. Int J Basic Clin Pharmacol 2013;2:71-76.

2. Mikail CN, Hearney E, Nemesure B. Increasing physician awareness of the common uses and contraindications of herbal medicines: utility of a case-based tutorial for residents. J Altern Complement Med 2003;9:571-576.

3. Zimmerman C, Kandiah J. A pilot study to assess students' perceptions, familiarity, and knowledge in the use of complementary and alternative herbal supplements in health promotion. Altern Ther Health Med 2012;18:28-33.

4. Gardiner P, Graham R, Legedza AT, Ahn AC, Eisenberg DM, Phillips RS. Factors associated with herbal therapy use by adults in the United States. Altern Ther Health Med 2007;13:22-29.

5. Little JW.; Complementary and alternative medicine: impact on dentistry. Oral Surg Oral Med Oral Pathol Oral Radiol Endod., 2004; 98:137-145
6. Kara B. Herbal product use in a sample of Turkish patients undergoing haemodialysis. J Clin Nurs 2009;18:2197-205

7. Rivera JO, Gonzalez-Stuart A, Ortiz M, Rodriguez JC, Anaya JP, Meza A. Herbal product use in non-HIV and HIV-positive Hispanic patients. J Natl Med Assoc 2005;97:1686-691.

8. Gardiner P, Graham R, Legedza AT, Ahn AC, Eisenberg DM, Phillips RS. Factors associated with herbal therapy use by adults in the United States. Altern Ther Health Med 2007;13:22-29.

9. Bent S. Herbal medicine in the United States: review of efficacy, safety, and regulation: grand rounds at University of California, San Francisco Medical Center. J Gen Intern Med 2008;23:854-859.

10. Tirona RG, Bailey DG. Herbal product-drug interactions mediated by induction. Br J Clin Pharmacol 2006;61:677-681.

11. Subapriya R, Nagini S; Medicinal properties of neem leaves: a review. Curr Med Chem Anticancer Agents, 2005; 5(2): 149-146.

12. Blakemore S. New herbal remedy safeguards. Primary Health Care 2011;21:6-7

13. Kelly JP, Kaufman DW, Kelley K, Rosenberg L, Anderson TE, Mitchell AA. Recent trends in use of herbal and other natural products. Arch Intern Med 2005;165:281-286.

14. Charantimath S, Oswal R Herbal Therapy in Dentistry: A Review. Innovative Journal of Medical and Health Science (2011) 1: $1-4$.

*Corresponding author:

Dr. Shivayogi M. Hugar, Department of Pedodontics and Preventive Dentistry, KLE Academy of Higher Education and Research

KLE VK Institute of Dental Sciences, Belagavi-590010

Phone: +91 9986436448

Email: dr.hugarsm@gmail.com

Financial or other Competing Interests: None. 